\title{
Tertiary Syphilis
}

National Cancer Institute

\section{Source}

National Cancer Institute. Tertiary Syphilis. NCI Thesaurus. Code C128414.

A stage of syphilis that occurs fifteen to thirty years after the initial infection; it can include gumma formation and cardiovascular or central nervous system involvement (neurosyphilis). 